\title{
Nebulised antibiotics for adults with cystic fibrosis
}

\author{
A K Webb, M E Dodd
}

During adolescence most patients with cystic fibrosis become chronically colonised with Pseudomonas aeruginosa. Acquisition of this organism is associated with a worse prognosis.

The emphasis of care is to delay the progression of pulmonary sepsis which is responsible for almost the total mortality of patients with cystic fibrosis. Repeated sputum culture of $P$ aeruginosa confirms chronic infection and it is then impossible to eradicate. Regular courses of intravenous antibiotics have improved survival by reducing sputum load and maintaining pulmonary function, but they interfere with the activities of daily living. The prescription of nebulised antibiotics for domiciliary use by patients with cystic fibrosis is increasing. However, experienced physicians working in cystic fibrosis centres have shown considerable variability in their prescribing practices. $^{2}$

\section{Clinical indications}

DELAY OR PREVENTION OF CHRONIC

COLONISATION WITH P AERUGINOSA

The introduction of nebulised colistin at the time of initial colonisation with $P$ aeruginos may reduce and delay chronic colonisation, ${ }^{3}$ defined as three consecutive positive sputum defined as three consecutive positive sputum
cultures within six months. In an uncontrolled cultures within six months. In an uncontrolled
trial nebulised colistin given to seven children trial nebulised colistin given to seven children
with cystic fibrosis reduced the frequency of positive cultures from $46 \%$ to $6 \% .^{3}$ In a controlled prospective study a combination of nebulised colistin and oral ciprofloxacin significantly prevented or delayed chron sigfection with $P$ aeruginosa for 18 months. ${ }^{4}$ These results suggest a role for nebulised antibiotics when the organism is first isolated from sputum. No trials have been published on the use of nebulised antibiotics at the time of diagnosis of cystic fibrosis before $P$ aeruginosa has been cultured from the sputum.

PREVENTION OF CLINICAL DETERIORATION IN PATIENTS CHRONICALLY INFECTED WITH

$P$ AERUGINOSA

Regular aerosolised antibiotics have been used for patients chronically infected with $P$ aeruginosa to reduce the rate of deterioration. An early controlled trial compared twice daily administration of $80 \mathrm{mg}$ nebulised gentamicin combined with $1 \mathrm{~g}$ carbenicillin against placebo. ${ }^{5}$ In the group that received the active drugs for six months there was a reduction in hospital admissions for infective exacerbations and pulmonary function was maintained. Aerosolised therapy was cost effective because of the reduced hospital costs.

Ceftazidime was compared with a combination of gentamicin with carbenicillin in a crossover study in which saline was used as the placebo. ${ }^{6}$ Each arm of the crossover period lasted for four months. Both active drug regimens were equally effective in increasing body weight and improving lung function compared with placebo. These results suggest that only one nebulised antibiotic is required for efficacy. A recent short term study recruited 71 patients into a controlled trial of placebo versus high dose nebulised tobramycin, $600 \mathrm{mg} /$ day. $^{7}$ The high dose of tobramycin was used to increase the bactericidal dose of antibiotic in the sputum against tobramycin sensitive $P$ aeruginosa. There was a significant improvement in pulmonary function and a reduction of $P$ aeruginosa in the sputum. Bacterial resistance patterns were similar during the active and nephrotoxicity was observed. These results suggest that high dose nebulised tobramycin is clinically effective, safe, and does not promote bacterial resistance.

Nebulised tobramycin, $80 \mathrm{mg}$ twice daily, was evaluated in a long term open study (mean duration 20 months) in 14 patients with a mean age of 13.3 years. ${ }^{8}$ Clinical parameters improved and hospital admissions decreased. There was a reduction in one or more inflammatory markers (antibody serum titres to $P$ aeruginosa, elastase, exotoxin $\mathrm{A}$, alkaline phosphatase) in eight patients. No tobramycin was detected in 50 of 70 blood samples. Intermittent tobramycin resistance developed in five patients (but only in $6.2 \%$ of strain strains) and persisted in only one patient at the end of the study. These results suggest that long term nebulised aminoglycosides are safe, clinically effective and, by reducing the bacterial antigen load, may diminish the systemic host immune response.

A review of five randomised controlled trials showed benefit for nebulised antipseudomonal antibiotic therapy with no demonstrable adantibiotic therapy with no demonstrable adverse effects. ${ }^{9}$ There is no evidence to suggest
that nebulised antibiotics used as an adjunct that nebulised antibiotics used as an adjunct to a course of intravenous antibiotics augment
clinical improvement. ${ }^{10}$ Nebulised antibiotics should not be used as an alternative to intravenous antibiotics for an infective exacerbation.

Assessment and administration

PATIENT ASSESSMENT

Patients should be carefully assessed before treatment with nebulised antibiotics is started. 
A recent sputum culture should be used to determine which antibiotic to prescribe according to resistance patterns. Colistin is infrequently used intravenously and resistance to $P$ aeruginosa is uncommon. Each patient should be given a hospital supervised dose after chest physiotherapy and spirometric tests should be physiotherapy and spirometric tests should be performed before and immediately after chal-
lenge. Maximal bronchoconstriction to nebulised antibiotics usually occurs immediately after administration. ${ }^{11}$ Bronchoconstriction is usually related to hypertonicity of the antibiotic solution. ${ }^{1213}$ Prevention of bronchoconstriction may be achieved by altering the tonicity by dilution with water or half normal saline. ${ }^{14}$

dilution with water or half normal saline.
It is recommended that patients use nebuIt is recommended that patients use nebu-
lised antibiotics after physiotherapy and bronchodilators to ensure maximum deposition and protection from bronchoconstriction. ${ }^{11}$ Patients should be provided with a mouthpiece rather than a face mask to maximise pulmonary deposition. ${ }^{15}$ Relaxed tidal volume breathing through the mouth and not volume breathing through the mouth and not
the nose ${ }^{16}$ is recommended for patients using nebulised antibiotics. Finally, patient compliance levels should be checked after a period of domiciliary use. Irregular usage is not recommended and is a reason for cessation.

DISTRIBUTION OF NEBULISED ANTIBIOTIC IN THE LUNG

Overall, about $10 \%$ of a nebulised drug is delivered to the lungs. A study in volunteers and five mechanically ventilated patients given $300 \mathrm{mg}$ nebulised tobramycin found that $5.5 \%$ of the initial dose was excreted in the urine of both groups. A piece of normal lung tissue was removed from the ventilated patients who were undergoing thoracotomy and mean concentrations of $5.5 \mu \mathrm{g} / \mathrm{g}$ and $3.6 \mu \mathrm{g} / \mathrm{g}$ were found at four and 12 hours. ${ }^{17}$

Systemic absorption of nebulised aminoglycosides does occur in patients but the amount absorbed proportional to the dose delivered as measured by urinary excretion is small $(0.5 \%){ }^{18}$

Although the concentration of aerosolised antibiotic in bronchial secretions may not always achieve bactericidal levels, sublethal concentrations may diminish bacterial virulence factors. ${ }^{19}$

CHOICE OF ANTIBIOTIC AND FORMULATION The polymyxin antibiotic colistin and the aminoglycosides tobramycin and gentamicin are the most commonly prescribed nebulised antibiotics. Colistin is currently the only antibiotic licensed in the UK for inhalation. Tobramycin probably has greater activity than gentamicin against $P$ aeruginosa. Infrequently used antibiotics for nebulisation include ceftazidime, carbenicillin, and ticarcillin. Colistin has excellent antipseudomonal activity and is probably the first line choice for nebulised use. Pseudomonas aeruginosa resistance is rare but Burkholderia cepacia resistance is total.

Table 1 Commonly used nebulised antibiotics

\begin{tabular}{|c|c|c|}
\hline \multirow{2}{*}{$\begin{array}{l}\text { Antibiotic } \\
\text { Colistin* } \\
\text { Gentamicin } \\
\text { Tobramycin }\end{array}$} & \multicolumn{2}{|c|}{ Daily dose } \\
\hline & \multicolumn{2}{|c|}{$\begin{array}{l}2 \text { mega units } 12 \text { hourly } \\
80 \mathrm{mg} 12 \text { hourly } \\
80 \mathrm{mg} 12 \text { hourly }\end{array}$} \\
\hline \multicolumn{3}{|c|}{ * Colistin is the only antibiotic licensed in the UK for inhalation } \\
\hline Table 2 Iso & iic solution. & of colistin \\
\hline Dose & Volume fill & Solvent \\
\hline $\begin{array}{l}2 \text { mega units } \\
2 \text { mega units } \\
2 \text { mega units }\end{array}$ & $\begin{array}{l}4 \mathrm{ml} \\
2.5 \mathrm{ml} \\
3 \mathrm{ml}\end{array}$ & $\begin{array}{l}2 \mathrm{ml} \text { water }+2 \mathrm{ml} 0.9 \% \mathrm{NaCl} \\
1.5 \mathrm{ml} \text { water }+1 \mathrm{ml} 0.9 \% \mathrm{NaCl} \\
2 \mathrm{ml} \text { water }+1 \mathrm{ml} 0.9 \% \mathrm{NaCl}\end{array}$ \\
\hline
\end{tabular}

Nebulised antibiotics are prescribed twice a day for domiciliary use. Drugs and dosages are presented in tables 1 and 2 .

\section{ANTIBIOTIC SAFETY}

Resistance

Concern has been expressed that bacterial resistance will develop with the administration of sublethal twice daily doses of aerosolised antibiotics. Resistance does occur but is often intermittent and not related to clinical deterioration. ${ }^{58}$ There is no confirmatory evidence that the use of aerosolised antibiotics in the presence of resistant bacteria leads to increased colonisation of the bronchial tree with these resistant organisms. Burkholderia cepacia is always resistant to colistin which should not be used if $y$ pathogen in the sputum. There is no published literature on the use of nebulised antibiotics for $B$ cepacia.

Environmental safety

Concern has been expressed that the liberal use of nebulised antibiotics may be a health hazard to medical personnel and constitute a threat to the hospital and home environment. Staff caring for patients using nebulised antibiotics have experienced bronchoconstriction and cutaneous rashes. Although it has been suggested that polluting the hospital atmosphere may lead to the establishment of resistant organisms, particularly on intensive care units where patients may receive nebulised antibiotics following transplantation to maintain airways sterility, there is no published medical evidence to support this.

In hospital a nebuliser should be fitted with a high efficiency breathing filter on the expiratory port to prevent environmental contamination and patients with cystic fibrosis can stop their nebulised antibio receiving intravenous antibiotics. It is advisable for patients to receive them in a separate area. At home patients should nebulise their antibiotics in a separate room. They do not need to vent their exhaled antibiotics for safety reasons although they may wish to do so to eliminate the odour. If they have a sibling with cystic fibrosis they should use a filter. 
Table 3 Order of preference for compressor/nebuliser systems for nebulised antibiotics (1) Standard flow rate compressor (61/min) with a breath enhanced open vent nebuliser. This (2) High flow rate compressor ( $81 / \mathrm{min}$ ) with a breath enhanced open vent nebuliser. High flow ate compressor (81mi) with a Veath nabuliser. This is recommended (4) Standard flow rate compressor (6//min) with a Venturi nebulise Mouthpieces rather than face masks should be used except for infants or younger children who
will not tolerate them.
Patient safety

The respiratory side effects of aerosolised antibiotics are mainly limited to bronchoconstriction at time of delivery. Cutaneous rashes are rare but may occur with nebulised drugs. A sore mouth may be due to candidiasis drugs. A sore mouth may be due to candidiasis
although the incidence is not known. If a mask although the incidence is not known. If a mask
is used the face should be washed after antiis used the face sh
biotic nebulisation.

During pregnancy intravenous aminoglycosides cross the placenta. Although repeated courses of high dose intravenous aminoglycosides have been associated with deafness and renal damage, ${ }^{20}$ these side effects have not been reported with nebulised therapy. ${ }^{8}$ Aerosolised antibiotics should be prescribed with caution during pregnancy but, on th available evidence, are not contraindicated.

Nebulisers may act as a source of bacterial contamination. ${ }^{2122}$ Nosocomial acquisition of Burkholderia cepacia has been associated with the use of humidifiers and nebulisers ${ }^{23}$ and respiratory equipment has been implicated as the source of spread of $B$ cepacia in immune suppressed patients. ${ }^{24}$ It is recommended that patients should clean their nebulisers after every use and some can be placed in a dishwasher. ${ }^{2}$ It is important that cystic fibrosis patients colonised with $B$ cepacia should have their own compressors and they should not be used subsequently by patients infected with Paeruginosa. An electrical compressor should have an inlet filter which should be changed every three months. There should also be a bacterial filter in line to prevent the patient receiving contaminants from the compressor. These should be changed annually or between patients. Incorrect care of a nebuliser/compressor system may result in an inefficient system for drug delivery and a potential hazard to the patien and environment.

ANTIBIOTIC DELIVERY

Antibiotics are available as a solution or powder and are reconstituted as a solution using saline or water to a volume of $4 \mathrm{ml}(2.5 \mathrm{ml}$ for low residual volume nebuliser). Nebulisation should take no longer then 10 minutes in order to ensure maximum compliance. The combination of an electrical compressor and a nebuliser must then be matched to maximise effective delivery of the nebulised antibiotic to the patient. The requirements of a system for nebulising antibiotics may differ from other solutions. Continuous improvements are taking place to meet patient requirements. Some recommended systems are shown in table 3 .

1 Wilmott RW, Tyson SL, Mathews DJ. Cystic fibrosis survival rate: the influence of allergy and Pseudomonas aeruginosa. Am ₹ Pis Child 1985;139:669-71

Taylor R, Hodson M. Cystic fibrosis: antibiotic prescribing practices in t993;7:535-40

3 Littlewood J, Miller MG, Ghoneim AT, Ramsden CH. Nebulised colomycin for early colonisation in cystic fibrois. Valerius NH, Koch C, Hoiby N. Prevention of chronic
Pseudomonas aeruginosa colonisation in cystic fibrosis by Pseudomonas aeruginosa colonisation in cystic fibrosis by
early treatment. Lancet 1991;338:725-6. early treatment. Lancet 1991;338:725-6.
Hodson ME, Penketh ARL, Batten JC. Aerosol carbenicillin and gentamicin treatment of Pseudomonas aeruginosa in-
fection in patients with cystic fibrosis. Lancet 1981;ii: Tead RJ, Hodson ME Batten JC. Inhaled ceftazidime compared with gentamicin and carbenicillin in older patients infected with Pseudomonas aeruginosa. Br $\mathcal{F} D i$ Ramsey BW, Dorkin HL, Eisenberg JD, Gibson RL, Harwood IR, Kravitz RM, et al. Efficacy of aerosolised tobramycin in patients with cystic fibrosis. N Engl F Med 1993; Steinkamp G, Tummler B, Gappa M, Albus A, Potel J, Goring G, et al. Long-term tobramycin aerosol therapy in cystic fibrosis. Pediatr Pulmonol 1989;6:91-8.
Mukhopadhyay S, Singh M, Cater J, Ogston S, Franklin
M, Olver RE. Nebulised antipseudomonal antibiotic therpy in cystic fibrosis: a meta-analysis of benefits and risks. Thorax 1996;51:364-8.

Stephens D, Garey N, Isles A, Levison H, Gold R. Efficacy of inh Dald tobramycin in the treatment of pulmonary
exacerbations in children with cystic fibrosis. Pediatr Infect Dis 1983;2:209-1

Maddison , Dodd M, Webb AK. Nebulised colistin causes
chest tightness in adults with cystic fibrosis. Respir Med 1994;88:145-7. Chua HL, Collis GG, Le Souef PN. Bronchial response to Respir F 1990;3:114-6.

13 Littlewood JM, Smye SW, Cunliffe H. Aerosol antibiotic

treatment in cystic fibrosis. Arch Dis Child 1993;68:788-92
14 Dodd ME, Maddison I, Abbott J Webb AK. The effect of the tonicity of nebulised colistin on chest tightness and
lung function in adults with cystic fibrosis. Eur Respir $\mathcal{F}$

$1993 ; 6: 515 \mathrm{~S}$.
15 Everard ML, Hardy JG, Milner AD. Comparison of nebulised aerosol deposition in the lungs of healthy adults
following oral and nasal inhalation. Thorax 1993;48:10456 New

6 Newman SP, Woodman G, Clate SW Depositon of arbenicillin aerosols in cystic fibrosis: effects of nebulise system and breathing pattern. Thorax 1988;43:318-22. Caillon J, Juvin ME, et al. Lung distribution and pharamokinetics 1279-82.

18 Smith AL, Ramsey BW, Hedges DL, Hack B, WilliamsWarren J, Weber A, et al. Safety of aerosol tobramycin Pediatr Pution for 3 months to patients with cystic fibrosis. 19 Geers TJ, Cooke RE. The effect of sublethal levels of antibiotics on the pathogenicity of Pseudomonas aeruginosa 20 McRorie T, Bosso J, Randolf L. Aminoglycoside ototoxicity in cystic fibrosis. 1089uation by high frequency audiometry. Barnes KL, Clifford R, Holgate ST, Murphy D, Comber
P, Bell E. Bacterial contamination of home nebulisers. BMf 1987;295:812. Pitchford KC, Corey M, Highsmith AK, Periman R, Bannatyne R, Gold R, et al. Pseud
tamination of cystic fibrosis pat tamination of cystic fibrosis patient
equipment. ₹ Pediatr 1987;111:212-6. 3 Burdge DR, Nakiena EM, Noble MA. Case-control and vector studies of nosocomial acquisition or Pseudomonas
cepacia in adult patients with cystic fibs Hosp Epidemiol 1993; 14:127-30.

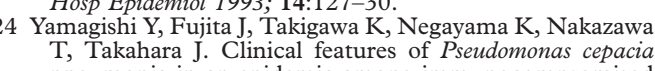
pneumonia in an epidemic among immunocompromised 